\title{
Putting contract research organisations on the radar
}

\author{
Mariëtte van Huijstee ${ }^{1}$ and Nuria Homedes ${ }^{2}$
}

${ }^{1}$ Researcher, SOMO (Centre for Research on Multinational Corporations), Amsterdam, The Netherlands, email m.vanhuijstee@somo.n

${ }^{2}$ Associate Professor, University of Texas, School of Public Health, USA

This article is based on a research report with the same title published by the Centre for pesearch on Multinational for Research on Multinationa Corporations (SOMO) Corporate Social and Ethical Research (CSER) and Salud y Farmacos (SyF). It is available from SOMO's website http:// somon/publications-nt/ Publication 3615-nl

\begin{abstract}
There is a trend for pharmaceutical companies to contract third parties to conduct the clinical trials that are needed to test their drugs. This trend is referred to as outsourcing, and the companies that carry out the work are called contract research organisations. In addition, clinical trials are increasingly conducted in nontraditional trial regions, which are mainly lowand middle-income countries. This trend is called offshoring. The combination of outsourcing and offshoring poses serious risks for the ethical treatment of participants in clinical trials.
\end{abstract}

It is widely agreed that the offshoring of clinical trials to non-traditional trial regions like India and Peru should be scrutinised from an ethical perspective because of the vulnerability of an important part of the trial population. In order to receive medical treatment, these participants often have no alternative but to participate in a clinical trial. Their vulnerability, combined with a lack of independent oversight in many of the countries, creates serious ethical risks.

What happens when offshoring is combined with outsourcing? Do additional ethical risks arise when clinical trials are contracted out? Virtually all pharmaceutical companies publicly declare that they test their drugs in accordance with the highest ethical guidelines, such as the Declaration of Helsinki. But how do pharmaceutical companies safeguard their commitments when they outsource clinical trial activities to contract research organisations (CROs) in poor regions? These are the central questions that are addressed in this paper, which draws on a recent research report that was based on interview and secondary data from India, Argentina, Peru and Brazil, as well as on interviews with pharmaceutical companies and clinical trial experts.

\section{The market for CROs}

Nearly $70 \%$ of the total research and development (R\&D) costs for drugs are accounted for by clinical trials. In 2008, US pharmaceutical companies spent $\$ 32.2$ billion on trials (Pharmaceutical Research and Manufacturers of America, 2010). Pharmaceutical companies are under pressure to bring more new drugs to the market while at the same time they have to cut their R\&D budgets. Time is money: the faster a drug is brought to market, the longer the company can enjoy the financial benefits of a patent. The pharmaceutical industry is responding to these challenges by pursuing consolidations in the form of mergers and acquisitions, reducing head counts in $\mathrm{R} \& \mathrm{D}$, and increasing the outsourcing of R\&D to CROs.

The CROs offer pharmaceutical companies access to extra global capacity, to extra knowledge and to new technologies without their having to make huge investments, and enable them to convert large fixed costs into variable costs. Currently, about half of the clinical trial activities of pharmaceutical companies are outsourced to CROs. The worldwide CRO market was estimated to be $\$ 24$ billion in 2010 (Kim \& Kardum, 2010). In the past decade, the global spending by pharmaceutical companies on contract clinical services has been growing at an annual rate of $13.4 \%$ on average (Tufts Center for the Study of Drug Development, 2010).

The CRO sector is highly fragmented, with over 1100 CROs worldwide, although more than twothirds of all CROs are based in the USA (Cipher, 2008). Contract research organisations come in many shapes and sizes. Some specialise in services in certain areas, and some offer the whole spectrum of services in a drug development process around the world. This latter group comprises the global full-service CROs, which have a presence in all emerging markets. The five largest CROs (Quintiles, Covance, PPD, Charles River Laboratories and ICON) hold $45 \%$ of the total market between them (Kim \& Kardum, 2010).

The way the major CROs profile themselves reflects the drivers for outsourcing: they conduct clinical trials faster and at lower costs, and they have established facilities in all new popular trial locations - Latin America, India, China, Central and Eastern Europe and Russia (Jakovcic, 2009). These regions are popular for their fast recruitment of trial participants, the presence of a broad spectrum of diseases, the availability of human resources and technical skills, the availability of populations with differing ethnic responses to drugs, who may also be 'treatment naïve', and because of the tightening of testing regulations in the traditional test regions (Thomis \& Smita, 2006).

In the past 5 years, $37.3 \%$ of the participants in pivotal trials used for marketing authorisation applications (MAAs) submitted in the European Union (EU) were recruited in non-traditional research countries. Compared with Western Europe and North America - the traditional trial regions these regions are often less regulated (or offer a regulatory maze), have a less developed healthcare system and have a relatively vulnerable population. Furthermore, our research findings in Argentina, India and Brazil indicate inadequate oversight by authorities and ethics committees. 
The clinical trial business is a welcome economic activity in most non-traditional trial regions. In India, as well as in Brazil, the regulatory process has recently been modified to expedite the approval of clinical trials, which is a decisive factor to attract CROs. These organisations can operate without registration or accreditation (or simply registration at the chamber of commerce may be enough to start testing drugs on humans). Currently, all the major CROs are present in the popular trial locations. In Peru, $70 \%$ of all trials are conducted by CROs and in Argentina the figure is about $30 \%$.

\section{Ethical risks associated with outsourcing}

Clinical trials inherently bring up many ethical issues, irrespective of where the trials are conducted or who is conducting them. This is because they involve exposing humans to health risks for the health benefits of other humans in the future. Clinical trials are crucial for the development of new drugs that might save millions of lives in the future. But certainly not all clinical trials serve this 'higher' goal of health for all. Many interests both economic and non-economic - play a role in clinical trials: those of the sponsor, of the principal investigators, of the CROs, of participants and of future patients. These interests are weighed time and again, and create so-called ethical 'minefields' in which participants may suffer.

Experts and practitioners have serious concerns over trade-offs between costs, speed and quality of clinical trials. In many outsourcing models, CROs must bid against other CROs to win research contracts. In competing for contracts, 'all the incentives are to do [the work] fast', with the risk of compromising quality. The CROs' predominant interest is simply to deliver a product (often clinical data that meet market entrance requirements) on time and under budget (Mirowski \& Van Horn, 2005; Shuchman, 2007).

Experts and practitioners are worried about the 'commodification' of clinical trials by means of functional outsourcing to CROs: CROs meet their deadlines by breaking the conduct of each study into discrete steps and emphasising their speedy completion. As CRO critics have said, the 'commodification' of research projects has begun to 'kill' clinical research, and a CRO is reduced to a 'data-production sweatshop', where 'everyone's very focused on the data', rather than on the totality of the knowledge required to determine whether a drug is worth pursuing further (Shuchman, 2007). Tasks are further scattered and oversight is further burdened when CROs themselves subcontract parts of the clinical trial work. The interview data indicated that such subcontracting does take place, sometimes without regulatory agencies and sponsors being informed.

\section{Oversight by pharmaceutical companies}

In our interviews, the pharmaceutical companies that sponsor trials confirmed they had concerns about the performance of CROs. In response they have developed elaborate mechanisms to select, monitor and evaluate CROs in order to guarantee compliance with relevant laws and ethical standards. In fact, these mechanisms greatly increase the costs of CRO-sponsor contracts, which affect the business case for working with CROs, and make some sponsors wary of outsourcing clinical trial management altogether. The fact that some companies refrain from outsourcing because of high monitoring costs leaves us wondering about the stringency of the oversight by those companies that do choose to contract CROs.

At the policy level, the protection of participants in clinical trials managed by CROs in non-traditional trial regions often seems to be in order, but what happens in practice is hard to verify independently, as monitoring reports are not public. Furthermore, European MAA procedures for drugs that have involved testing outside Europe do not include independent verification of the ethical conduct of the trials. This situation of lacking independent oversight obviously leaves a lot of room for improvement in the protection of clinical trial participants in non-traditional trial regions.

Notwithstanding the claims of sponsors, interviews with CROs indicate that the stringency of monitoring mechanisms varies widely among sponsors, which obviously creates opportunities for underperforming CROs. Indeed, stories continue to surface about unethical trials, which supports such concerns (Jenkins, 2010; Wemos, 2010; Lakhani, 2011).

\section{Conclusion}

There is no proof that clinical trials executed by CROs breach ethics guidelines more often than other trials. However, the blurring of responsibilities and fragmentation of clinical tasks through contracting and subcontracting, combined with cost and time pressures, clearly increases the risk that ethical treatment of clinical trial participants is given the lowest priority. In this context it remains an area of grave concern that the parties that earn most money with the trials - CROs and sponsors - seem to be the most important monitors in non-traditional trial regions.

\section{References}

Cipher (2008) Global Contract Research Organization (CRO) Industry: Overview and Trends, 2008. Available at http:// www.cipher-sys.com/Global \% 20Contract \% 20Research \% 20 Organizations.pdf (accessed 6 March 2012).

Jakovcic, K. (2009) The CRO market outlook: emerging markets, leading players and future trends. Business Insights. Available at http:// www.marketresearch.com/Business-Insights-v893/CRO-OutlookEmerging-leading-players-2428184 (accessed 6 March 2012).

Jenkins, P. (2010) Body Hunters. Television documentary.

Kim, I. \& Kardum, K. (2010) Evotec AG. Close Brothers Seydler, Available at http://ebookbrowse.com/evotec-initial-coverage-201007-30-pdf-d109426765 (accessed 6 March 2012).

Lakhani, N. (2011) From tragedy to travesty. Independent, 15 November.

Mirowski, P. \& Van Horn, R. (2005) The contract research organization and the commercialization of scientific research. Social Studies of Science, 35, 503-548. 
Pharmaceutical Research and Manufacturers of America (2010) Pharmaceutical Industry Profile 2010. Available at http://www. phrma.org/sites/default/files/159/profile_2010_final.pdf (accessed 6 March 2012).

Shuchman, M. (2007) Commercializing clinical trials - risks and benefits of the CRO boom. New England Journal of Medicine, 357 1365-1368.
Thomis, J. \& Smita, D. (2006) Outsourcing strategies. In Outsourcing Clinical Development (eds J. E. Winter \& J. Baguley), p. 14. Gower Publishing.

Tufts Center for the Study of Drug Development (2010) Tufts CSDD Outlook 2010. Available at http://csdd.tufts.edu/_documents/ www/Outlook2010.pdf (accessed 6 March 2012).

Wemos (2010) The Globalization of Clinical Trials: Testimonies from Human Subjects. Wemos.

\section{THEMATIC} PAPER

\title{
Psychiatric medicines in India: why public healthcare facilities and $a$ thriving generics industry cannot assure access and affordability
}

\author{
Anita Kotwani
}

Associate Professor, Department of Pharmacology, V.P. Chest Institute, University of Delhi, Delhi, India, email anitakotwani@ gmail.com
This commentary highlights the poor availability of essential psychiatric medicines at public sector facilities in India and illustrates why even a flourishing generics industry does not assure access to affordable psychiatric medicines for most Indian patients. The paper outlines the Indian government's pricing regulations and then enumerates recommendations for reform.

Approximately $20 \%$ of the adult population of India is affected by psychiatric disorder (Math \& Srinivasaraju, 2010). Although mental illnesses are highly prevalent in low- and middle-income countries such as India, $70-80 \%$ of these psychiatric illnesses remain untreated or do not receive evidence-based care (Patel, 2008). Additionally, patients in less developed health systems pay for medicines out of pocket, as they cannot rely on insurance or publicly financed healthcare. To address the debilitating impact of untreated mental illness, countries like India must prioritise psychiatric screening at primary health centres and improve access to psychiatric medicines.

The next section of this paper evaluates the availability of essential psychiatric medications at public facilities and private retail outlets in India. The low availability of medicines at governmentrun facilities forces patients to purchase medicines from the private sector. Although Indian generics appear relatively cheap, the low purchasing power of Indian consumers renders pharmaceutical treatment inaccessible for most psychiatric patients. The following section describes the marketing strategies of manufacturers and retailers in the thriving generics industry. Manufacturers aggressively market branded medicines to clinicians, and retailers push non-premium branded-generics directly to patients - although the two versions are chemically identical. Consequently, manufacturers and retailers have a vested interest in raising the profit margins associated with branded medicines and non-premium branded-generics respectively. The paper goes on to outline the government's pricing regulations and then enumerates recommendations for reform.

\section{Current access to essential medicines}

Notionally, Indian public facilities must provide free care and medicines. Most citizens naturally turn to the public sector for treatment. Out-ofpocket payments, however, account for up to $80 \%$ of health financing in India. Additionally, more than $70 \%$ of health spending on out-patient treatment goes towards purchasing medicines (Creese et al, 2004).

Surveys conducted using methodology developed by the World Health Organization (WHO) and Health Action International (HAI) found poor availability of a basket of 27 essential medicines for the treatment of common acute and chronic diseases in six Indian states (Kotwani et al, 2007, 2009). This basket included amitriptyline, diazepam and fluoxetine - frontline drugs for treating mental disorders. Median availability of surveyed medicines (as a proportion of the 20-60 public facilities surveyed in various states) ranged from $0 \%$ to $30 \%$. A subsequent $\mathrm{WHO} / \mathrm{HAI}$ survey in the national capital, Delhi, measured the availability of 50 essential medicines in the public sector (results available on the Health Action International website, www.haiweb.org). The mean availability of these medicines (as a proportion of the 83 public facilities surveyed) was $33 \%$, while the mean availability for amitriptyline, diazepam and fluoxetine was $6 \%, 11 \%$ and $4 \%$. These three medicines are included in the Delhi State Essential 